\title{
Role of thioredoxin reductase 1 and thioredoxin interacting protein in prognosis of breast cancer
}

\author{
Cristina Cadenas*1, Dennis Franckenstein 1,2, Marcus Schmidt ${ }^{3}$, Mathias Gehrmann4, Matthias Hermes², \\ Bettina Geppert2, Wiebke Schormann², Lindsey J Maccoux¹,2, Markus Schug², Anika Schumann5 , Christian Wilhelm5, \\ Evgenia Freis2,6, Katja Ickstadt6, Jörg Rahnenführer6, Jörg I Baumbach¹, Albert Sickmann¹ and Jan G Hengstler*2
}

\begin{abstract}
Introduction: The purpose of this work was to study the prognostic influence in breast cancer of thioredoxin reductase 1 (TXNRD1) and thioredoxin interacting protein (TXNIP), key players in oxidative stress control that are currently evaluated as possible therapeutic targets.

Methods: Analysis of the association of TXNRD1 and TXNIP RNA expression with the metastasis-free interval (MFI) was performed in 788 patients with node-negative breast cancer, consisting of three individual cohorts (Mainz, Rotterdam and Transbig). Correlation with metagenes and conventional clinical parameters (age, pT stage, grading, hormone and ERBB2 status) was explored. MCF-7 cells with a doxycycline-inducible expression of an oncogenic ERBB2 were used to investigate the influence of ERBB2 on TXNRD1 and TXNIP transcription.

Results: TXNRD1 was associated with worse MFI in the combined cohort (hazard ratio $=1.955 ; P<0.001$ ) as well as in all three individual cohorts. In contrast, TXNIP was associated with better prognosis (hazard ratio $=0.642 ; P<0.001$ ) and similar results were obtained in all three subcohorts. Interestingly, patients with ERBB2-status-positive tumors expressed higher levels of TXNRD1. Induction of ERBB2 in MCF-7 cells caused not only an immediate increase in TXNRD1 but also a strong decrease in TXNIP. A subsequent upregulation of TXNIP as cells undergo senescence was accompanied by a strong increase in levels of reactive oxygen species.
\end{abstract}

Conclusions: TXNRD1 and TXNIP are associated with prognosis in breast cancer, and ERBB2 seems to be one of the factors shifting balances of both factors of the redox control system in a prognostic unfavorable manner.

\section{Introduction}

Control mechanisms of reactive oxygen species (ROS) play a crucial role in tumor development. Transformed cells are known to generate more ROS than normal cells $[1,2]$. Importantly, ROS not only contribute to tumor progression by amplifying genomic instability but transformed cells use ROS signals to drive proliferation [1]. Conversely, ROS addiction may render tumor cells more vulnerable to apoptosis or senescence [3,4] because they depend on constantly increased basal levels of ROS, and an additional increase may exceed toxic thresholds.

*Correspondence: cristina.cadenas@isas.de, hengstler@ifado.de

1 Department of Bioanalytics, Leibniz-Institut für Analytische Wissenschaften ISAS - e.V., Bunsen-Kirchhoff-Straße 11, Dortmund 44139, Germany

2 Systems Toxicology, Leibniz Research Centre for Working Environment and

Human Factors (IfADo) at the TU Dortmund University, Ardeystraße 67, Dortmund 44139, Germany

Full list of author information is available at the end of the article
Thioredoxin reductase 1 (TXNRD1) and thioredoxin interacting protein (TXNIP; also called thioredoxin binding protein 2 or vitamin D3-upregulated protein 1) [5] are key players in oxidative stress control.

TXNRD1 reduces and activates thioredoxin, an oxidoreductase containing a dithiol-disulfide active site, which in turn reduces oxidized cysteine residues on cellular proteins. Importantly, a reducing environment mediated by thioredoxin is required for effective DNA binding of redox-sensitive transcription factors, including p53 and NF- $\mathrm{kB}[6,7]$. Thioredoxin binds ROS before they can harm cells and thus protects cells against oxidative stress. In addition to its critical role in the regulation of cellular redox homeostasis, thioredoxin has multiple actions in the cell - such as activation of ribonucleotide reductase, inhibition of apoptosis signal regulating kinase 1 and induction of hypoxia inducible factor 1 (HIF-1) and vas- 
cular endothelial growth factor (VEGF) - which contribute to many hallmarks of cancer, such as increased proliferation, inhibited apoptosis and angiogenesis [8].

In contrast to TXNRD1, which supports thioredoxin function, TXNIP binds to and inhibits the reduced form of thioredoxin [9-11], blocking its activity as well as its interaction with other factors, including apoptosis signal regulating kinase 1 . TXNIP therefore functions as a proapoptotic protein [12]. As for thioredoxin, multifunctional roles of TXNIP are known $[13,14]$ that point out the crucial role of TXNIP as a link between pathways of redox regulation, antioxidant defense, energy metabolism and cell growth and survival $[15,16]$. A summary of the roles of these key players of the thioredoxin system is provided in Figure 1.
The thioredoxin redox system has been suggested recently as a therapeutic target for cancer therapy $[17,18]$, based on the observation that thioredoxin is overexpressed in many aggressive tumors and that siRNA-mediated knockdown of TXNRD1 decreased tumor progression and metastasis in mice [19]. Several inhibitors of the thioredoxin pathway have been shown to have antitumor activity in mice bearing breast, colon and renal xenografts [20-22]. In addition, high thioredoxin expression in prechemotherapy tumor samples has been reported to be associated with resistance to docetaxel in primary breast cancer $[23,24]$.

Despite the ongoing evaluation of the thioredoxin system as a therapeutic target and the central role of TXNRD1 and TXNIP in oxidative stress control, little is known about their prognostic relevance. Increased<smiles>N#CC1CCCCC1SSc1ccccc1</smiles>

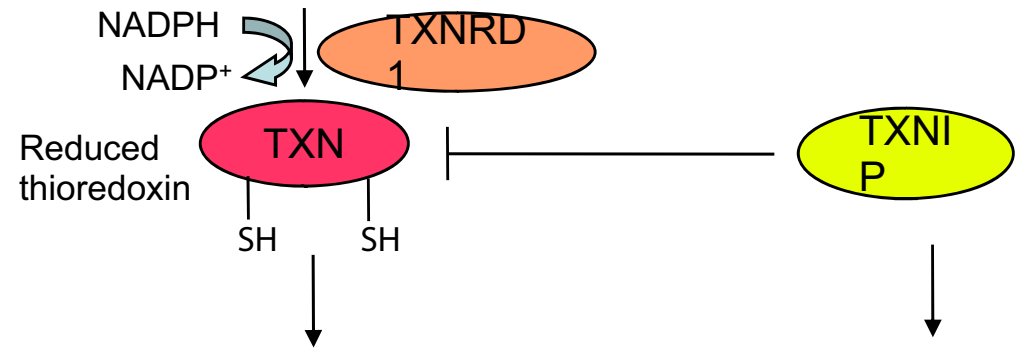

\begin{tabular}{|l|l|}
\hline Target Protein & Output \\
PRDX & ROS scavenging \\
RR & DNA synthesis \\
NF-KB, AP-1, SP-1 & Activation of transcription factors \\
HIF-1 $\alpha$, VEGF & Angiogenesis \\
ASK-1, PTEN & Inhibition of apoptosis \\
\hline
\end{tabular}

\begin{tabular}{|l|l|}
\hline Target Protein & Output \\
\hline TXN & Inactivation \\
\hline PLZF, FAZF, HDAC1 & Modulation of transcription \\
\hline P16, CDKs & Regulation of cell cycle \\
\hline pVHL & Degradation of HIF-1 $\alpha$ \\
\hline$?$ & Glucose and FA metabolism \\
\hline$?$ & Immune cell response \\
\hline
\end{tabular}

Figure 1 Scheme of cellular functions of the cytoplasmic thioredoxin system. Thioredoxin reductase 1 (TXNRD1) reduces thioredoxin 1 (TXN), which in turn reduces oxidized cysteins in cellular proteins and scavenges peroxides by peroxiredoxins (PRDX), thus protecting cells against oxidative stress. TXN stimulates ribonucleotide reductase (RR) activity and supports DNA synthesis. TXN stimulates the transcriptional activity of nuclear factor KB (NF-KB), activator protein 1 (Fos/Jun) (AP-1) and specificity protein 1 (SP-1), and elevates hypoxia inducible factor 1a (HIF-1a) protein levels, which in turn influence vascular endothelial growth factor (VEGF). TXN also binds to and inhibits the pro-apoptotic proteins apoptosis signal regulating kinase 1 (ASK-1) and phosphatase and tensin homolog (PTEN). All these events promote cell growth, inhibit apoptosis and increase angiogenesis in tumors, as reviewed elsewhere [8]. Thioredoxin interacting protein (TXNIP) binds and inhibits reduced TXN. TXNIP also interacts with several transcriptional co-repressors, such as promyelocytic leukemia zinc-finger (PLZF), Fanconi anemia zinc-finger (FAZF) and histone deacetylase 1 (HDAC1), and inhibits transcription of cyclin $A_{2}$, leading to reduced cell growth. TXNIP increases p16 and p27KIP1 protein levels, leading to cell cycle arrest. TXNIP also associates with the von Hippel-Landau protein ( $\mathrm{pVHL}$ ), enhancing the interaction between $\mathrm{PVHL}$ and HIF1a to promote nuclear export and degradation of HIF1a. The roles of TXNIP in the immune system and in human metabolism are not yet fully understood. For reviews, see [13,14]. CDK, cycline dependent kinase; FA, fatty acid; ROS, reactive oxygen species. 
expression of thioredoxin in human colorectal cancer is associated with decreased patient survival [25], whereas absence of thioredoxin expression in nonsmall-cell lung carcinoma is associated with a better outcome [26]. Decreased TXNIP expression in patients with diffuse large B-cell lymphoma has been shown to correlate with a poor prognosis [27]. To our knowledge, however, TXNRD1 expression and TXNIP expression have not yet been analyzed in relation to prognosis in breast cancer. In the present study we observed that high expression of TXNRD1 and low expression of TXNIP are associated with worse prognosis in breast cancer. Since both higher TXNRD1 expression and lower TXNIP expression were observed in ERBB2-status-positive tumors, we analyzed whether ERBB2 can influence these factors using a MCF7 cell line that allows conditional expression of an oncogenic version of ERBB2.

\section{Materials and methods Cultivation of MCF-7/NeuT cells and analysis of RNA expression patterns}

The MCF-7 breast carcinoma cell line was obtained from the American Type Culture Collection (LGC Standards $\mathrm{GmbH}$, Wesel, Germany), cultured at $37^{\circ} \mathrm{C}$ in a humidified $5 \% \mathrm{CO}_{2}$ air atmosphere, and transfected with pINSpBI-NeuT/EGFP and pcDNA3Neo/rtTA2 as described elsewhere [3]. Expression of NeuT, an oncogenic version of ERBB2, was induced by doxycycline (obtained as the hydrochloride salt from Sigma, Munich, Germany) at a final concentration of $1 \mu \mathrm{g} / \mathrm{ml}$ in all experiments. MCF-7/ NeuT cells were exposed to doxycycline for periods of 0 , 6, 12 and 24 hours as well as 3 and 14 days. Three independent repeat experiments were performed. Between each repeat experiment, the MCF-7/NeuT cells were cultivated for at least two passages. Cells were harvested using TRItidy G-Reagent (AppliChem GmbH, Darmstadt, Germany) and RNA was isolated subsequently according to the manufacturer's protocols and stored at $80^{\circ} \mathrm{C}$.

Before microarray analysis, RNA integrity and concentration were examined using an Agilent 2100 Bioanalyzer (Agilent Technologies, Palo Alto, CA, USA) with the RNA 6000 LabChip Kit (Agilent Technologies) according to the manufacturer's instructions. Microarray analysis was conducted at the microarray core facility of the Interdisziplinäres Zentrum für klinische Forschung (Faculty of Medicine, University of Leipzig, Germany). To create cDNA, the High Capacity cDNA Reverse Transcription Kit was used (Applied Biosystems, Darmstadt, Germany). The TaqMan technique was used for further gene expression analysis by quantitative real-time PCR and confirmation of microarray data. Ubiquitin $C$ was chosen as the reference gene and the untreated cells were taken as the controls. The expression assays used were
Hs00824723_m1 (ubiquitin C), Hs00197750_m1 (TXNIP) and Hs00917067_m1 (TXNRD1) (Applied Biosystems). The PCR conditions followed the standard specifications recommended by Applied Biosystems. For calculations of relative gene expression, we used the $2^{-\Delta \Delta C t}$ method as described by Schug and colleagues [28].

\section{Immunoblotting}

Immunoblot analysis was performed as described elsewhere $[3,29]$. The Neu antibody (sc-284; Santa Cruz Biotechnology, Heidelberg, Germany) and the p44/42 mitogen-activated protein kinase antibody (\#9102; Cell Signaling, Boston, MA, USA) were diluted at 1:1,000 and were incubated for 2 hours at room temperature. The phospho-p44/p42 mitogen-activated protein kinase Tyr202/Thr204 antibody (\#9101; Cell Signaling) and the phospho-Akt Ser473 (\#9271; Cell Signaling) were diluted at 1:1,000 and incubated overnight at $4^{\circ} \mathrm{C}$. The phosphop38 mitogen-activated protein kinase Thr180/Tyr182 (3D7) (\#9215; Cell Signaling) was diluted at 1:500 and incubated overnight at $4^{\circ} \mathrm{C}$. The Txnip (Vdup1) (sc166234; Santa Cruz) antibody was diluted 1:250 and the Txnrd1 antibody (ab 16840; Abcam, Cambridge, UK) was diluted 1:1,000. Both antibodies were applied overnight at $4^{\circ} \mathrm{C}$. The $\beta$-actin antibody (clone AC-74; Sigma Aldrich, Munich, Germany) was diluted 1:5,000 and was incubated for 30 minutes at room temperature. Horseradish peroxidase-conjugated secondary antibodies were obtained from Cell Signaling (anti-rabbit-HRP, \#7074) or from Sigma (anti-mouse-HRP, A9044) and were diluted $1: 10,000$ in $5 \%$ bovine serum albumin/Tris-bufffered saline Tween 20. Protein signals were detected by enhanced chemiluminiscence (PerkinElmer LAS, Rodgau-Jügesheim, Germany).

\section{Detection of malondialdehyde as a thiobarbituric acid or an $\mathrm{N}$-methyl-2-phenylindole complex}

Malondialdehyde (MDA) is a major degradation product of lipid hydroperoxides and is widely used as a marker of lipid peroxidation. To estimate the content of MDA in a sample we performed two analytical methods.

First, we measured thiobarbituric acid reactive substances via high-performance liquid chromatography according to the procedure described [30]. Aqueous trichloroacetic acid in the presence of hexane and butylated hydroxytoluene was used to homogenize the sample. Within this reaction a complex of MDA and 1,3diethyl-2-thiobarbituric acid (DETBA) is formed. The chromophore of the MDA-DETBA adduct was then chromatographed on a high-performance liquid chromatography column and quantified by fluorescence emission at $553 \mathrm{~nm}$ with an excitation at $532 \mathrm{~nm}$.

Second, we used a spectrophotometric assay based on a reaction of MDA with $N$-methyl-2-phenylindole 
(Bioxytech MDA-586; Oxis Research, Foster City, CA, USA). One molecule of MDA reacts with two molecules of $N$-methyl-2-phenylindole. The resulting stable carbocyanine dye shows a maximum absorption at $586 \mathrm{~nm}$ and was detected spectrophotometrically. For MDA estimation, eight measurements of three independent experiments were performed.

\section{Patient characteristics, tissue specimens and gene array analysis}

Three recently described cohorts of 788 node-negative breast cancer patients who did not receive chemotherapy were analyzed [31]. The combined cohort consisted of three individual cohorts: the Mainz cohort $(n=200)$, the Rotterdam cohort $(n=286)$ and the Transbig cohort $(n=$ 302).

The Mainz study cohort consists of 200 lymph nodenegative breast cancer patients treated at the Department of Obstetrics and Gynecology of the Johannes Gutenberg University Mainz between 1988 and 1998 [31]. Patients of the Mainz cohort were all treated with surgery and did not receive any systemic therapy in the adjuvant setting. The established prognostic factors (histological grade, tumor size, age at diagnosis, and steroid receptor status) were collected from the original pathology reports of the gynecologic pathology division within our department. Patients' characteristics have been published by Schmidt and colleagues [31] and are described in Additional file 1. For all tumors, samples were snap-frozen and stored at $80^{\circ} \mathrm{C}$. Gene expression profiling of the patients' RNA was performed using the Affymetrix HG-U133A array and the GeneChip System as described [31]. These data have been deposited in the National Center for Biotechnology Information Gene Expression Omnibus (GEO) and are accessible [GEO:GSE11121].

Results obtained from the Mainz cohort were validated in two previously published microarray datasets. Two breast cancer Affymetrix HG-U133A microarray datasets including patient outcome information were downloaded from the National Center for Biotechnology Information GEO data repository. The first dataset, the Rotterdam cohort [32], represents 180 lymph node-negative relapsefree patients [GEO:GSE2034] and 106 lymph node-negative patients that developed a distant metastasis. None of these patients had received systemic neoadjuvant or adjuvant therapy (Rotterdam cohort). The original data were recalculated to a mean target intensity (TGT) of 500. The second dataset, the Transbig cohort, consists of 302 samples from breast cancer patients that remained untreated in the adjuvant setting after surgery [33,34]. GEO sample record numbers of samples [GEO:GSE6532, GEO:GSE7390] used for analysis are listed in the supplementary tables previously published by Schmidt and col- leagues [31]. Raw .cel file data were processed by MAS 5.0 using a TGT of 500 .

Ethical approval for the analysis of RNA levels was required and granted by the local ethical committee (Landesärztekammer Rheinland-Pfalz, reference 837.139.05(4797)).

\section{Statistical analysis}

Univariate and multivariate Cox models were applied to analyze a possible association of TXNRD1 and TXNIP RNA expression ( $\log _{2}$ transformed) with prognosis. Disease-free survival was computed from the date of diagnosis to the date of local recurrence of disease, or distant metastasis, or cancer of the contralateral breast, or death from cancer. The metastasis-free survival interval (MFI) was computed from the date of diagnosis to the date of diagnosis of distant metastasis. Patients who died of an unrelated cause were censored at the date of death. Survival times were compared using Kaplan-Meier plots and the log-rank test. Since the frequency distributions of TXNRD1 and TXNIP did not perfectly match a normal distribution (Additional file 2) we used nonparametric tests for comparison of groups, such as the Mann-Whitney test for unpaired data.

Dichotomization was performed as described by Schmidt and colleagues [35,36]. Briefly, the cut-off points differentiating between high and low expression were identified in the combined cohort of patients from Mainz, from Rotterdam and from the Transbig group (Additional file 3). Similar bimodal distributions and cutoff points were observed in each individual cohort (Additional file 4). Cut-off points of 10 (estrogen receptor), 12.6 (ERBB2) and 4.9 (progesterone receptor) could therefore be used for all cohorts. Dichotomization was performed using these cut-off points to generate the following dichotomous variables: ERBB2 status, estrogen receptor status, progesterone receptor status and hormone receptor status (which is positive when only one of both estrogen or progesteron receptor status is positive).

Concerning histological grading, the patients were dichotomized into grade III versus grade I and grade II, and $\mathrm{pT}$ stage into $\mathrm{pT}_{2}$ and $\mathrm{pT}_{3}(>2 \mathrm{~cm})$ versus $\mathrm{pT}_{1}(\leq 2$ $\mathrm{cm}$ ) (for patient characteristics see Additional file 1).

Correlations were analyzed using the Spearman correlation test. All $P$ values are two-sided. As no correction for multiple testing was performed, the values should be regarded as descriptive measures. All analyses were performed using SPSS17.0 (SPSS Inc., Chicago, IL, USA).

\section{Results}

TXNDR1 and TXNIP are associated with prognosis in breast cancer

To study a possible association with the MFI, we analyzed our cohort (Mainz cohort) of patients and validated the 
results in two previously published cohorts (Rotterdam and Transbig cohorts). All patients were node-negative and did not receive chemotherapy. In the Mainz cohort, high TXNRD1 RNA expression was associated with a higher hazard ratio $(\mathrm{HR}=1.920 ; P=0.032)$ of metastasis (Table 1). In contrast, TXNIP was associated with a decreased HR $(\mathrm{HR}=0.598 ; P=0.017)$ (Table 1$)$. Similar results were obtained in the Rotterdam cohort, the Transbig cohort and the combined cohorts (Table 1).

Besides MFI, which captures the time between surgery and the occurrence of a distant metastasis, disease-free survival and overall survival were documented in the Mainz cohort. Disease-free survival comprises metastasis as well as local recurrence or carcinomas at the contralateral breast, whereas overall survival represents the time interval until breast-cancer-specific death. When analyzing disease-free survival and overall survival (Table 2), significant associations with TXNRD1 and TXNIP were also obtained.

Kaplan-Meier analysis was used to visualize the association between metastasis-free survival time and TXNDR1 as well as TXNIP (Figure 2). The time interval until occurrence of metastasis was shorter for patients with TXNRD1 expression higher than the median compared with patients with relatively low expression levels (Figure 2a). In contrast, patients with high TXNIP had longer MFI compared with patients with low TXNIP (Figure $2 b)$.

In conclusion, the influence of TXNRD1 and TXNIP could be confirmed in three independent cohorts of node-negative breast cancer patients.

\section{TXNDR1 and TXNIP in relation to known biological motives} in breast cancer

In recent years, the genome-wide search for markers predicting prognosis in breast cancer has led to a global picture in which three coordinates representing important biological processes have outstanding prognostic consequences $[31,35,36]$ : the proliferation metagene, consisting of a group of genes indicating transition from slow to fast proliferation; the B-cell and T-cell metagenes as markers for immune cell infiltration; and estrogen-receptordependent genes. In order to understand the role of TXNRD1 and TXNIP, we determined their relation to these three coordinates according to Freis and colleagues [37]. TXNRD1 showed a positive correlation $(R=0.465 ; P$ $<0.001)$ (Figure 3a) and TXNIP an inverse correlation $(R$ $=-0.367 ; P<0.001)$ with the proliferation metagene (Figure $3 \mathrm{~b})$. In addition, TXNRD1 showed an inverse correlation with the estrogen receptor metagene $(R=-0.432 ; P<$ $0.001)$ and a weakly positive correlation with the T-cell metagene $(R=0.230 ; P<0.001)$. TXNIP showed also a weakly positive correlation with the B-cell metagene $(R=$ 0.278; $P<0.001)$.

\section{TXNRD1 is associated with ERBB2 status}

To understand whether TXNRD1 and TXNIP are independent of conventional clinical parameters, we performed a multivariate Cox analysis (Table 3). For this purpose the regression model is usually adjusted for age, pT stage, grading, hormone (estrogen and progesterone) receptor as well as ERBB2 status [38]. In multivariate analysis, only TXNIP was independent of the clinical parameters $(P=0.037 ; \mathrm{HR}=0.654)$ whereas $T X N R D 1$

Table 1: Association of TXNRD1 and TXNIP RNA expression with metastasis-free survival

\begin{tabular}{|c|c|c|c|c|}
\hline & Prognostic factor & $P$ value & HR & $95 \% \mathrm{Cl}$ \\
\hline \multirow{2}{*}{$\begin{array}{l}\text { Mainz cohort } \\
(n=200)\end{array}$} & TXNRD1 RNA expression & 0.032 & 1.920 & 1.058 to 3.486 \\
\hline & TXNIP RNA expression & 0.017 & 0.598 & 0.392 to 0.912 \\
\hline \multirow{2}{*}{$\begin{array}{l}\text { Rotterdam cohort } \\
(n=286)\end{array}$} & TXNRD1 RNA expression & 0.004 & 1.755 & 1.196 to 2.576 \\
\hline & TXNIP RNA expression & $<0.001$ & 0.654 & 0.525 to 0.815 \\
\hline \multirow{2}{*}{$\begin{array}{l}\text { Transbig cohort } \\
(n=302)\end{array}$} & TXNRD1 RNA expression & 0.021 & 1.692 & 1.084 to 2.642 \\
\hline & TXNIP RNA expression & 0.013 & 0.639 & 0.448 to 0.910 \\
\hline \multirow{2}{*}{$\begin{array}{l}\text { Combined cohort } \\
(n=788)\end{array}$} & TXNRD1 RNA expression & $<0.001$ & 1.955 & 1.519 to 2.518 \\
\hline & TXNIP RNA expression & $<0.001$ & 0.642 & 0.554 to 0.743 \\
\hline
\end{tabular}

Thioredoxin reductase 1 (TXNRD1) RNA expression is associated with worse metastasis-free survival in patients with node-negative breast cancer in the univariate Cox analysis. In contrast, thioredoxin interacting protein (TXNIP) is associated with better metastasis-free survival. Results obtained in the Mainz cohort could be validated in the Rotterdam cohort and in the Transbig cohort of node-negative breast cancer patients. In the combined cohort of 788 patients, significant associations of TXNRD1 and TXNIP with metastasis-free survival were also obtained. HR: hazard ratio, $\mathrm{Cl}$, confidence interval. 
Table 2: Association of TXNRD1 and TXNIP RNA with disease-free survival and overall survival

\begin{tabular}{lllll}
\hline Survival & Prognostic factor & P value & HR & $\mathbf{9 5 \%} \mathbf{C l}$ \\
\hline Disease-free & TXNRD1 RNA expression & 0.010 & 2.025 & 1.180 to 3.476 \\
& TXNIP RNA expression & 0.012 & 0.617 & 0.423 to 0.899 \\
Overall & TXNRD1 RNA expression & 0.032 & 1.838 & 1.054 to 3.204 \\
& TXNIP RNA expression & 0.192 & 0.774 & 0.526 to 1.137 \\
\hline
\end{tabular}

In patients from the Mainz cohort $(n=200)$ of node-negative breast cancer in the univariate Cox analysis, an association of thioredoxin reductase 1 (TXNRD1) and thioredoxin interacting protein (TXNIP) RNA with disease-free survival and overall survival was observed. HR, hazard ratio; $\mathrm{Cl}$, confidence interval.

was not (Table 3). The reason for a lack of significance of TXNRD1 in the multivariate regression model was its association with higher $\mathrm{pT}$ stage $(P<0.001)$, higher grading $(P<0.001)$, negative hormone receptor status $(P<$ $0.001)$ and positive ERBB2 status $(P<0.001)$ (Additional file 5).

Because of the high clinical relevance of ERBB2, its correlation with TXNRD1 seemed particularly interesting and was analyzed in detail (Figure 4a). Higher TXNRD1 expression in ERBB2-status-positive patients compared with ERBB2-status-negative patients was observed in the Mainz cohort. This result was confirmed in the Rotterdam cohort and in the Transbig cohort (Figure 4a). In contrast to TXNRD1, the association with ERBB2 status was much weaker for TXNIP (Figure 4b). A trend towards lower TXNIP expression in ERBB2-status-positive patients was obtained that amounted to statistical significance only in the combined cohort with 788 patients (Figure 4b).

In conclusion, TXNRD1 showed a positive association and TXNIP a trend towards an inverse association with ERBB2 status.

\section{Other members of the thioredoxin pathway are also associated with prognosis in breast cancer}

The findings above prompted us to investigate whether other members of the thioredoxin pathway and downstream factors are also associated with prognosis of breast cancer. For this purpose we focused on the most prominent members of the thioredoxin pathway as summarized in Figure 1. The results demonstrate that not only expression of TXNIP and TXNRD1, the two factors influencing the thioredoxin pathway, but also downstream effectors show prognostic relevance in breast cancer (Table 4): thioredoxin $(T X N)$, the M2 subunit of ribonucleotide reductase (RRM2), peroxiredoxin 2 (PRDX2), HIF-1 $\alpha$ and VEGF were significantly associated with worse prognosis in the combined cohort as well as in at least one of the studied cohorts. The most convincing association was shown by $R R M 2$, with similar results in all three individual cohorts. Ribonucleotide reductase depends on activation by thioredoxin in order to reduce ribonucleotides to deoxyribonucleotides, and therefore supports DNA synthesis.

\section{TXNRD1 and TXNIP depend on ERBB2 expression in MCF-7 cells}

In order to analyze whether ERBB2 influences the levels of TXNRD1 and TXNIP expression, we used an MCF-7 cell line that allows doxycycline-dependent expression of an oncogenic version of ERBB2 (NeuT) by the Tet-on system $[3,4]$. Addition of doxycycline to the culture medium resulted in overexpression of oncogenic ERBB2 to levels seen in overexpressing breast carcinomas (Figure 5a). Induced ERBB2 overexpression was accompanied by increased phosphorylation of ERK1/2 and AKT/PKB, illustrating that doxycycline-induced ERBB2 is functional (Figure 5a).

As previously observed $[3,4]$, overexpression of oncogenic ERBB2 also induced cell cycle arrest and premature senescence in MCF-7 cells, which is accompanied by several phenotypical changes as can be observed in Additional file 6. ERBB2-triggered premature senescence has been found to be mediated by the P21 protein [3], and P21 mRNA levels were increased as early as 6 hours after onset of NeuT expression (Additional file 7).

Interestingly, induction of ERBB2 influenced the expression of TXNIP and TXNRD1 in a way that was reproducible in three independent experiments: the TXNIP transcript was immediately downregulated during the first 24 hours after addition of doxycycline, but recovered to initial levels at later time intervals (Figure 5b); the TXNRD1 transcript was immediately upregulated after doxycycline addition and fluctuated during the observed period, with levels remaining clearly higher than the initial (Figure 5b); and the TXNIP and TXNRD1 proteins showed the same trend as the corresponding transcripts, as assayed by immunoblotting. The onset of the upregulation and downregulation appeared somewhat delayed compared with that of the transcripts (Figure $5 \mathrm{c}$ ). In addition to this - as evidenced by analysis of the reaction of MDA with DETBA (thiobarbituric acid reactive substance assay) and with $N$-methyl-phenylindole (Figure $5 \mathrm{~d}$ ), as well as by a lipid peroxidation assay 
(a)

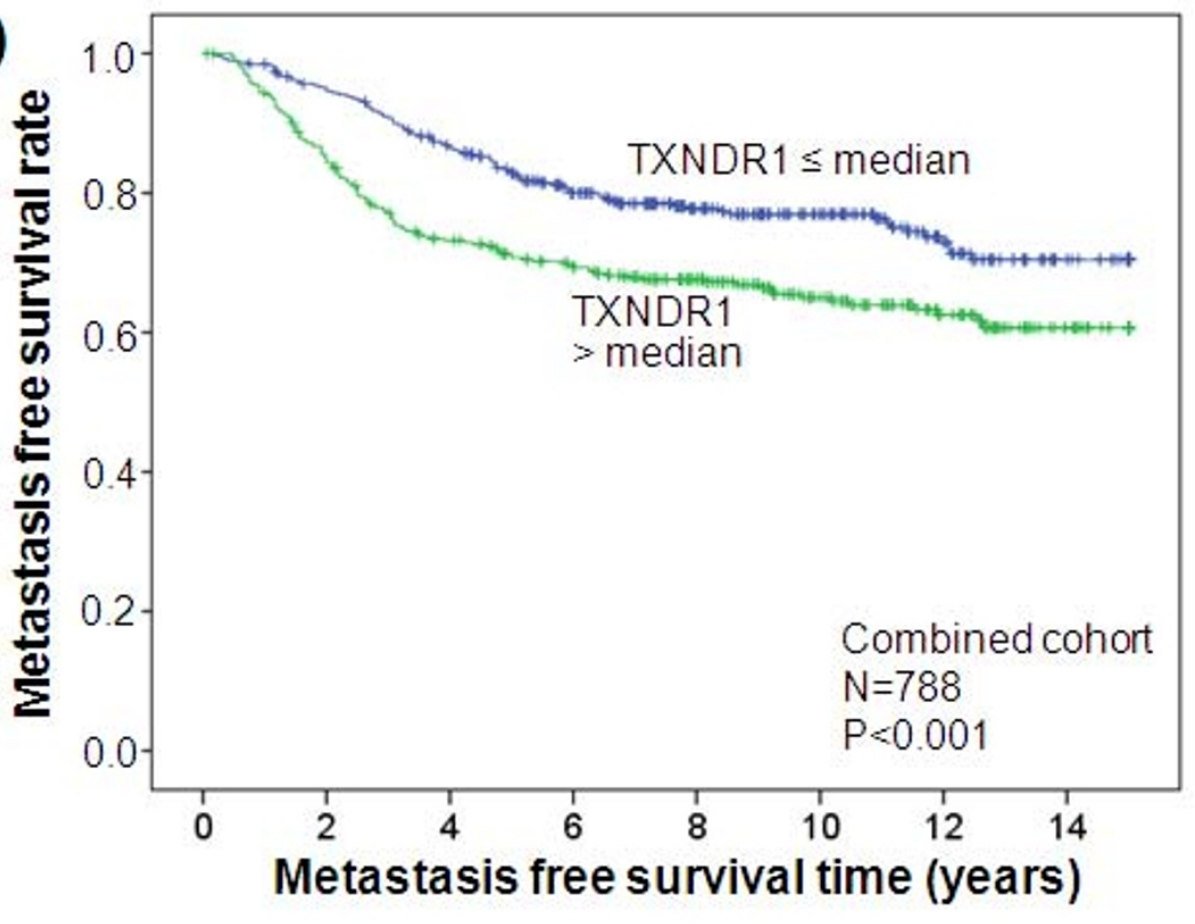

(b)

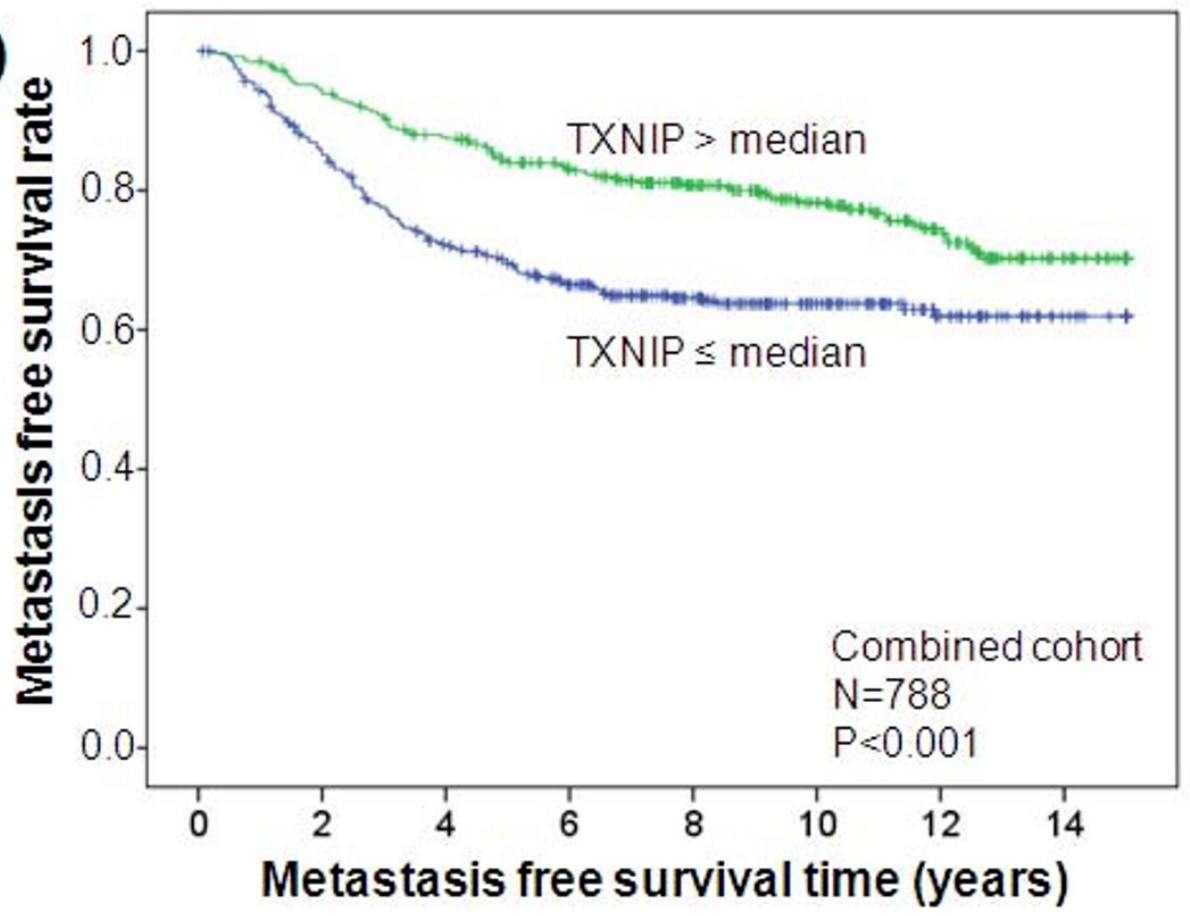

Figure 2 Association of TXNRD1 and TXNIP with metastasis-free survival time. (a) High thioredoxin reductase 1 (TXNDR1) expression is associated with shorter metastasis-free survival time, (b) whereas high thioredoxin interacting protein (TXNIP) expression is associated with longer metastasis-free survival time. The analysis included 788 patients with node-negative breast cancer who have not been treated by chemotherapy. Both TXNDR1 and TXNIP were dichotomized at the median. The log-rank test was used to assess statistical significance of the Kaplan-Meier plots. 

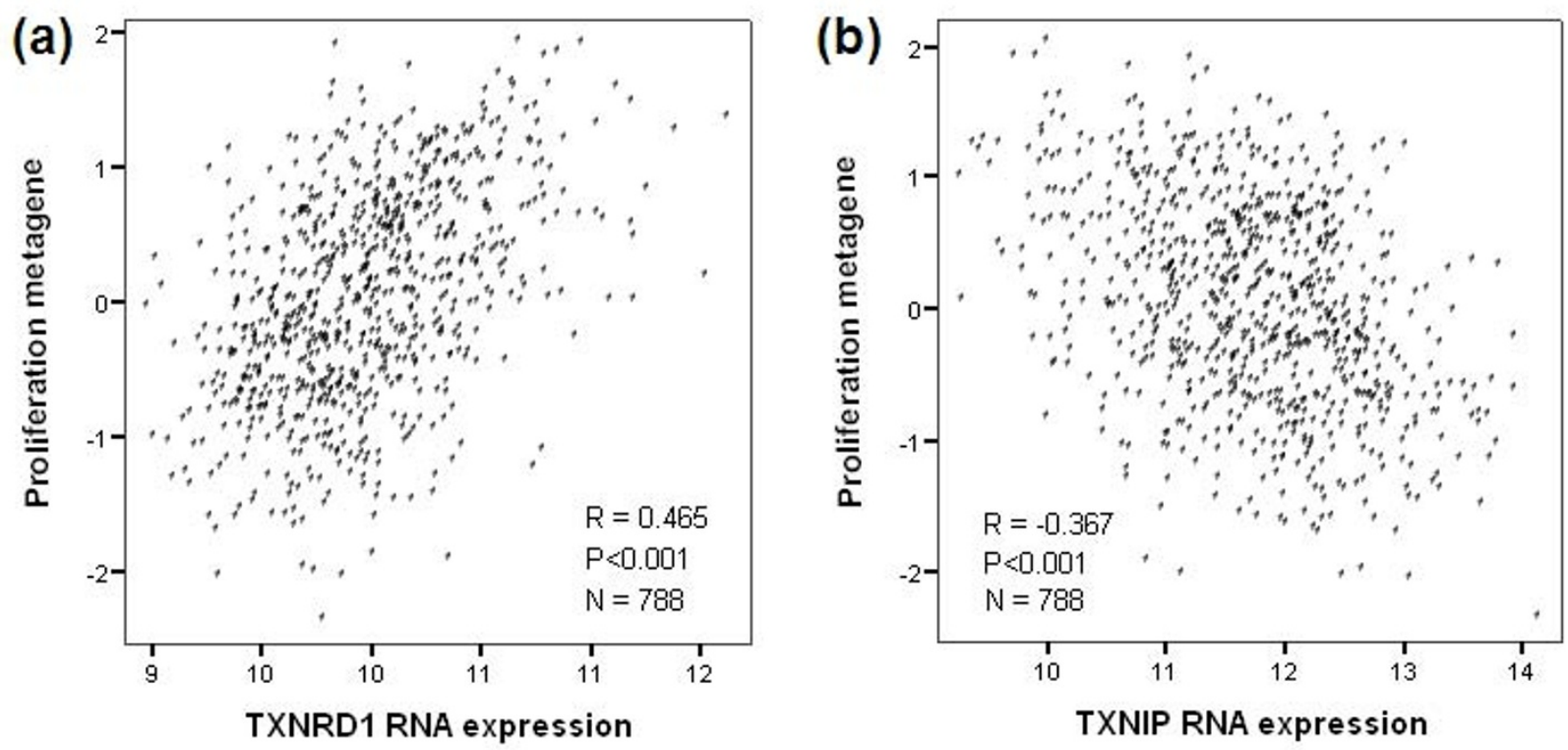

Figure 3 Correlation of TXNRD1 and TXNIP with the proliferation metagene. (a) Thioredoxin reductase 1 (TXNDR1) shows a positive correlation with the proliferation metagene, (b) whereas thioredoxin interacting protein (TXNIP) inversely correlates with the proliferation metagene. The analysis includes carcinomas of 788 patients with node-negative breast cancer.

(Additional file 8) - ROS were not increased at day 2 but were clearly increased at day 14 after onset of NeuT expression.

In conclusion, induced overexpression of ERBB2 caused alterations of TXNRD1 and TXNIP expression, whereby $T X N R D 1$ was upregulated and TXNIP downregulated. Both redox factors were influenced by ERBB2 in a way that, in our patient cohorts, was associated with worse prognosis.

\section{Discussion}

Targeting thioredoxin reductase and thioredoxin has been suggested recently as a basis for cancer therapy, including breast cancer $[22,39,40]$. The prognostic role of TXNRD1 and TXNIP, key players of the thioredoxin system, in node-negative breast cancer, however, has not yet been analyzed. We therefore studied three cohorts of patients who have not been treated by chemotherapy. In order to understand the role of TXNRD1 and TXNIP for the natural history of breast cancer it seemed relevant to focus on untreated patients, because the thioredoxin system has been reported to influence sensitivity of tumor cells to chemotherapy $[23,24,41]$. We observed that high expression of TXNRD1 was associated with worse prognosis, whereas high TXNIP expression was associated with better prognosis. These results obtained in our

Table 3: Multivariate analysis of the association between TXNRD1 and TXNIP RNA expression with metastasis-free survival

\begin{tabular}{llll}
\hline Prognostic factor & P value & HR & 95\% Cl \\
\hline Age (<50 years vs. $\geq 50$ years) & 0.511 & 1.176 & 0.725 to 1.910 \\
PT stage ( $\leq 2$ cm vs. $>2$ cm) & $<0.001$ & 3.526 & 1.866 to 6.661 \\
Histological grade (grade III vs. grades I and II) & 0.223 & 0.708 & 0.406 to 1.234 \\
Hormone receptora, ER or PR (negative vs. positive) & 0.865 & 0.951 & 0.529 to 1.707 \\
ERBB2 status (positive vs. negative) & 0.449 & 1.276 & 0.679 to 2.399 \\
TXNRD1 RNA expression & 0.162 & 1.445 & 0.862 to 2.420 \\
TXNIP RNA expression & 0.037 & 0.654 & 0.439 to 0.974
\end{tabular}

The analysis was carried out in patients with node-negative breast cancer in the univariate Cox analysis (Transbig cohort, $n=302$ ). $\mathrm{HR}$, hazard ratio; $\mathrm{Cl}$, confidence interval; TXNRD1, thioredoxin reductase $1 ; T X N I P$, thioredoxin interacting protein. aThe hormone receptor status (HR) is positive as soon as either the estrogen receptor (ER) status or the progesterone receptor (PR) status is positive. 


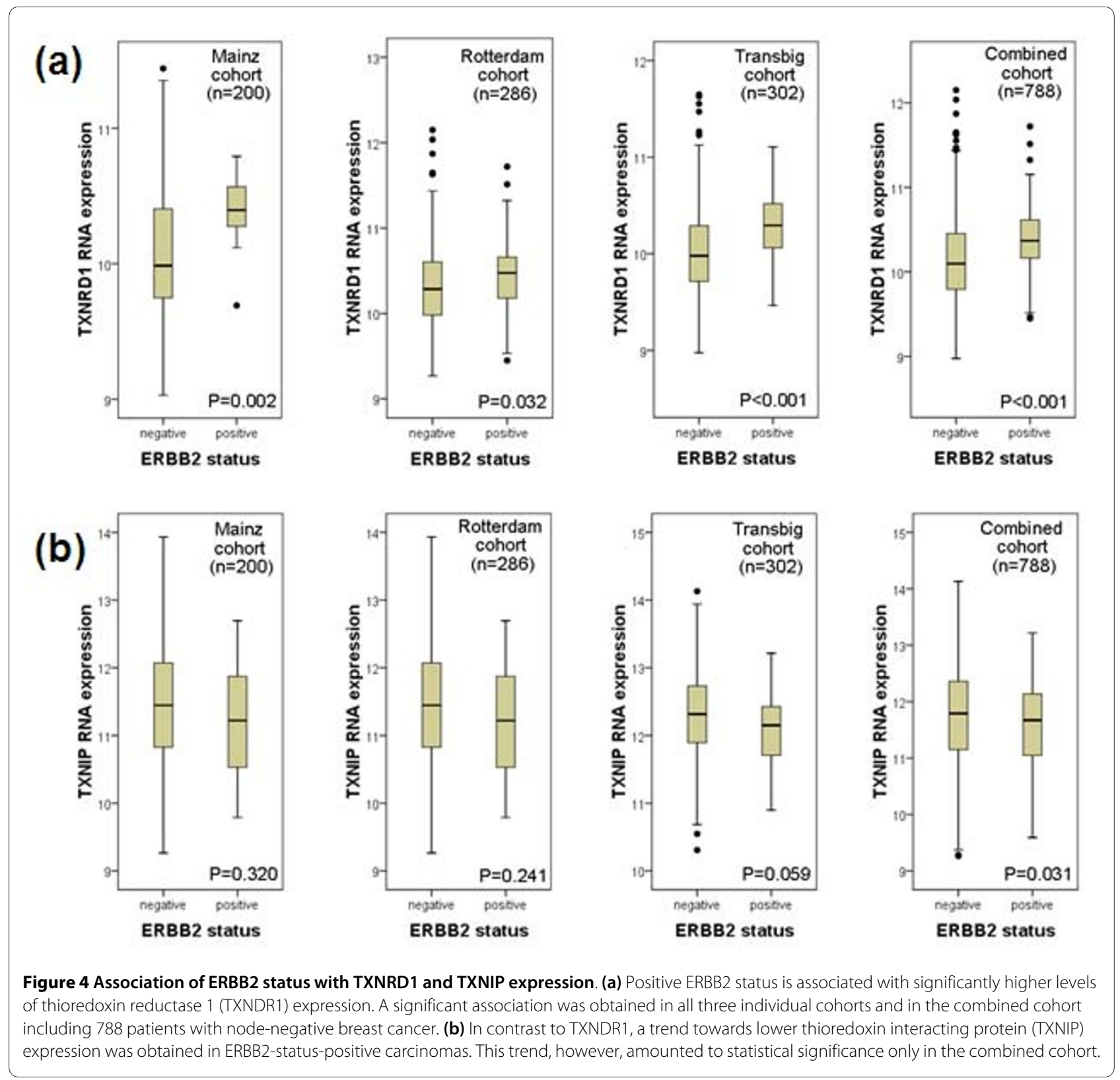

cohort, the Mainz cohort [31], could be confirmed in two independent, previously published cohorts - the Rotterdam cohort [32] and the Transbig cohort [33,34].

The inverse association of TXNRD1 and TXNIP with MFI found in this study supports the hypothesis that the maintenance of an active thioredoxin system is advantageous to the tumor cells because it limits oxidative damage and enables them to survive. Conversely, the important ROS-independent roles of TXNIP and thioredoxin might as well account for the promotion of tumorigenesis. It is noteworthy that both factors have opposite effects on HIF- $1 \alpha$, in a way that thioredoxin favors its increase and TXNIP its destabilization [42,43]. Additional associations with MFI found for thioredoxin and downstream factors of the thioredoxin pathway, including PRDX2, RRM2, HIF1A and VEGF, confirm the importance of the thioredoxin system in breast cancer regardless of its ROS-related or unrelated roles.

To better understand the interrelation of TXNRD1 and TXNIP with biologically relevant processes in breast cancer, we compared their expression levels with previously published metagenes [31,35,36,38]. The most striking correlations were observed with the proliferation metagene, showing that TXNDR1 is expressed strongly in fast proliferating tumors whereas TXNIP is expressed at low levels, which is in accordance with published data [4447]. This constellation fits to the negative prognostic influence of TXNRD1 and the favorable effect of TXNIP. 
Table 4: Association of other members and effectors of the thioredoxin pathway with metastasis-free survival

\begin{tabular}{|c|c|c|c|c|}
\hline & Prognostic factor & Pvalue & HR & $95 \% \mathrm{Cl}$ \\
\hline \multirow{6}{*}{$\begin{array}{l}\text { Mainz cohort } \\
(n=200)\end{array}$} & TXN RNA expression & 0.001 & 3.029 & 1.599 to 5.738 \\
\hline & RRM2 RNA expression & 0.001 & 1.598 & 1.205 to 2.120 \\
\hline & PRDX2 RNA expression & 0.066 & 1.950 & 0.957 to 3.975 \\
\hline & HIF1A RNA expression & 0.568 & 0.870 & 0.540 to 1.403 \\
\hline & VEGFA RNA expression & 0.485 & 1.206 & 0.713 to 2.042 \\
\hline & PTEN RNA expression & 0.313 & 0.774 & 0.470 to 1.273 \\
\hline \multirow{6}{*}{$\begin{array}{l}\text { Rotterdam cohort } \\
(n=286)\end{array}$} & TXN RNA expression & 0.067 & 1.428 & 0.976 to 2.091 \\
\hline & RRM2 RNA expression & $<0.001$ & 1.440 & 1.181 to 1.756 \\
\hline & PRDX2 RNA expression & 0.234 & 0.767 & 0.496 to 1.187 \\
\hline & HIF1A RNA expression & 0.003 & 1.545 & 1.160 to 2.058 \\
\hline & VEGFA RNA expression & 0.907 & 0.982 & 0.724 to 1.332 \\
\hline & PTEN RNA expression & 0.339 & 0.851 & 0.612 to 1.184 \\
\hline \multirow{6}{*}{$\begin{array}{l}\text { Transbig cohort } \\
(n=302)\end{array}$} & TXN RNA expression & 0.069 & 1.411 & 0.974 to 2.043 \\
\hline & RRM2 RNA expression & 0.003 & 1.354 & 1.107 to 1.655 \\
\hline & PRDX2 RNA expression & 0.687 & 1.129 & 0.627 to 2.033 \\
\hline & HIF1A RNA expression & 0.024 & 1.464 & 1.052 to 2.038 \\
\hline & VEGFA RNA expression & 0.045 & 1.393 & 1.007 to 1.926 \\
\hline & PTEN RNA expression & 0.197 & 0.802 & 0.573 to 1.121 \\
\hline \multirow{6}{*}{$\begin{array}{l}\text { Combined cohort } \\
(n=788)\end{array}$} & TXN RNA expression & $<0.001$ & 1.755 & 1.436 to 2.145 \\
\hline & RRM2 RNA expression & $<0.001$ & 1.469 & 1.298 to 1.663 \\
\hline & PRDX2 RNA expression & 0.004 & 1.423 & 1.120 to 1.807 \\
\hline & HIF1A RNA expression & $<0.001$ & 1.440 & 1.184 to 1.750 \\
\hline & VEGFA RNA expression & 0.033 & 1.239 & 1.018 to 1.508 \\
\hline & PTEN RNA expression & 0.243 & 0.885 & 0.720 to 1.087 \\
\hline
\end{tabular}

Association of TXN, RRM2, PRDX2, HIF1A, VEGF and PTEN RNA expression with metastasis-free survival in patients with node-negative breast cancer in the univariate Cox analysis. In the Mainz cohort, TXN and RRM2 RNA expressions are associated with worse metastasis-free survival. In the Rotterdam cohort, RRM2 and HIF1A are associated with metastasis-free survival. In the Transbig cohort, significant associations were found for RRM2, HIF1A and VEGFA. In the combined cohort of 788 patients, a significant association of all factors with metastasis-free survival, except PTEN, was obtained. $\mathrm{HR}$, hazard ratio; $\mathrm{Cl}$, confidence interval.

In addition, the estrogen receptor metagene was inversely correlated with TXNRD1. TXNRD1 also correlated with the T-cell metagene, which was surprising because the latter was associated with better prognosis in our previous studies [31]. Thioredoxin is known to be secreted by leukocytes and may exhibit cytokine-like properties in the extracellular environment [48]. A long controversial debate has been whether immune cell infiltration leads to a better prognosis of breast cancer by an attack on the tumor cells or whether secreted cytokines may cause on adverse effect creating a microenvironment that favors tumor cell proliferation [31].
Multivariate analysis adjusted for the conventional clinical parameters serves to identify whether a new factor adds some independent prognostic information to the already established parameters. In the Transbig cohort, TXNIP was independent of the established clinical parameters, whereas TXNRD1 was not. Of course a lack of influence in the multivariate Cox model does not exclude biological relevance. If several genes are responsible for progression of tumors from pT 1 to pT 4 it is likely that tumor stage, and not one of the many genes influencing tumor stage, will be influential in the multivariate regression model. In the case of TXNRD1, associations 


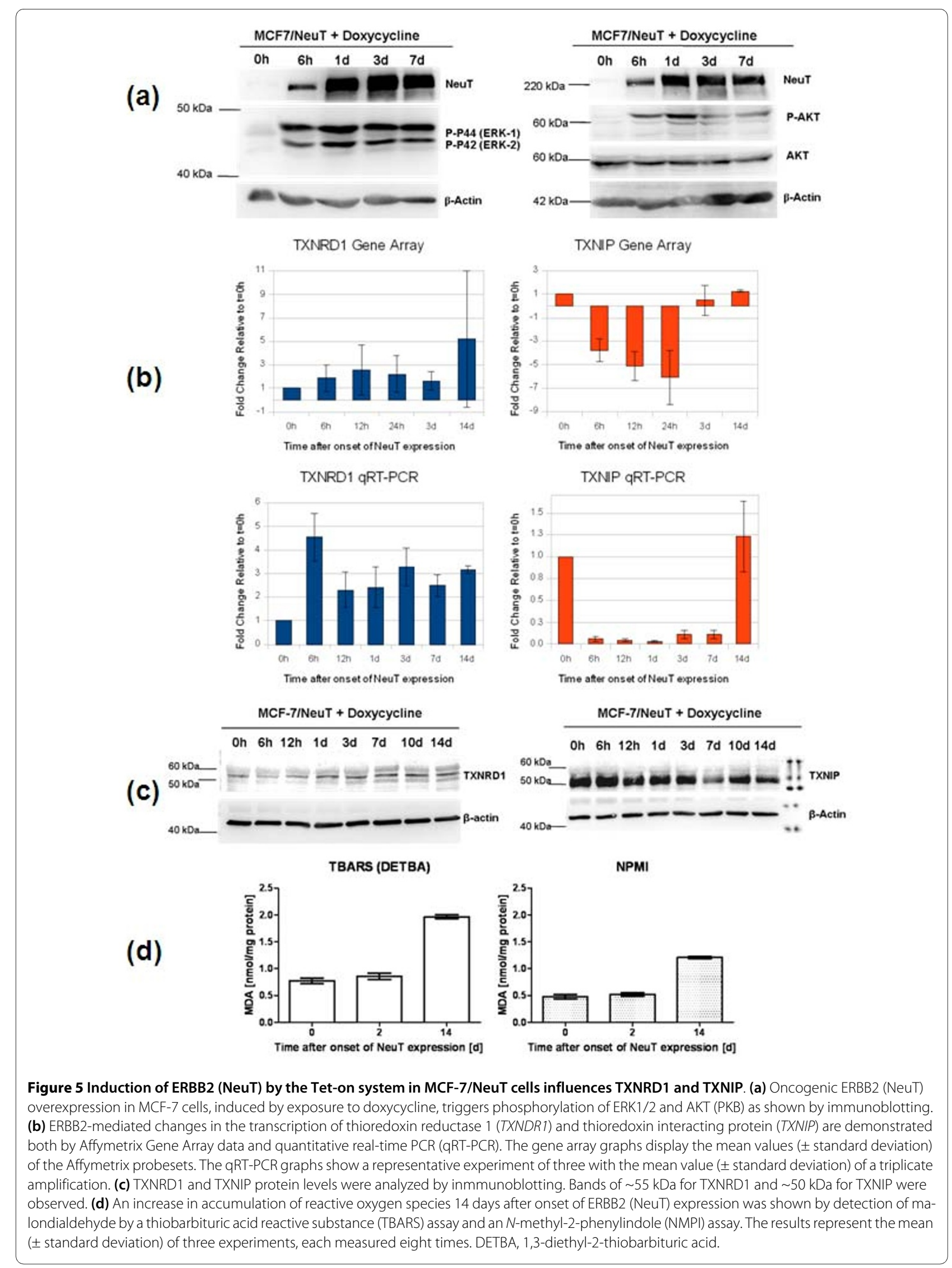




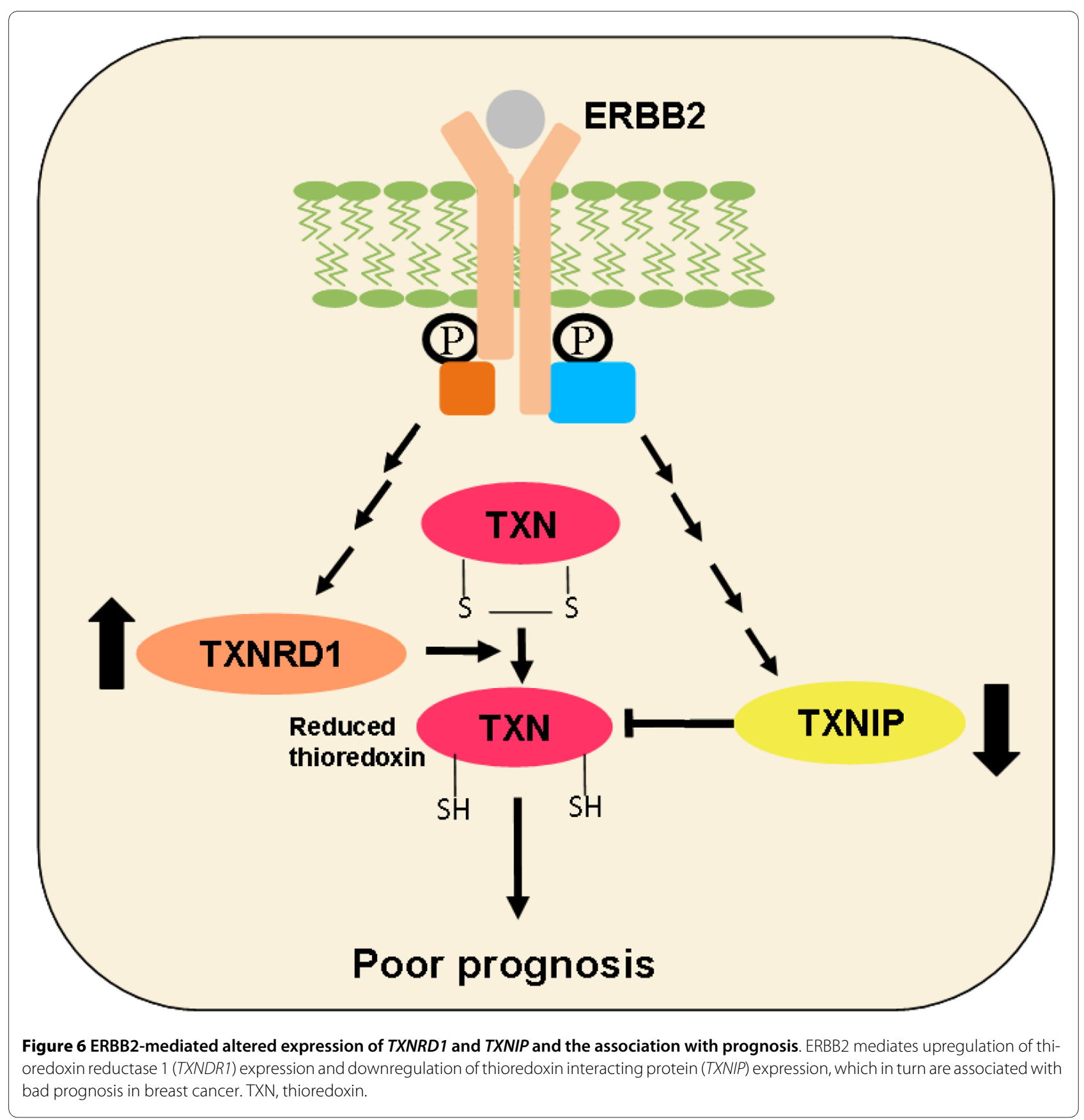

were observed with tumor grade and pT stage, hormone receptor status and ERBB2 status. We found the latter association particularly interesting, because it might be explained by an influence of overexpressed ERBB2 on TXNRD1 expression levels. When we studied TXNRD1 expression in ERBB2-status-positive versus ERBB2-status-negative carcinomas, significantly higher levels were obtained for ERBB2-status-positive tumors in all three individual study cohorts. Conversely, the difference in TXNRD1 expression levels was relatively small. This observation is not surprising, however, since an influence of ERBB2 will probably represent only one of several factors influencing TXNRD1 expression.

Inducible expression systems with erbB2 in mice or cell lines have contributed a lot to our understanding of erbB2-associated mechanisms [49,50]. To understand whether ERBB2 causes the increase in TXNRD1 expression or whether their association represents only an epiphenomenon of other primary events, we therefore applied the MCF-7/NeuT cell line, which allows inducible expression of an oncogenic version of ERBB2 (NeuT) $[3,4]$. Interestingly, switching on ERBB2 caused a clear increase in TXNRD1 mRNA and protein levels. A link 
between ERBB2 and TXNRD1 expression has been established in rat cardiomyocytes [51] where neuregulin $1 \beta$, a ligand of the ERBB receptor tyrosine kinase, upregulated the expression of thioredoxin and TXNRD1, among that of other genes involved in protection against oxidative stress, both at the mRNA and protein levels. This link supports the possibility that the immediate early increase in TXNRD1 mRNA levels observed after NeuT overexpression in our MCF-7/NeuT cell system is a direct response to ERBB2 signaling. The high TXNRD1 levels observed at relatively long periods (14 days) after NeuT induction could be due to the accumulation of ROS at this later stage. Since it is known that 4-hydroxynonenal, one of the major products of lipid peroxidation, can increase TXNRD1 mRNA levels via transcriptional activation of the NF-E2-related factor 2 signaling pathway and that TXNRD1 promoter contains an antioxidant response element [52], it is plausible that the observed accumulation of ROS in our cells at day 14 is contributing to the higher TXNRD1 expression at this time point.

Surprisingly, TXNIP was also influenced by NeuT but followed a completely different kinetic, with an initial downregulation of TXNIP transcript levels within 24 hours and a later recovery at 14 days. The immediate decrease of TXNIP mRNA upon ERBB2 expression suggests again a direct link between both factors. To our knowledge, nothing has so far been reported concerning a direct influence of ERBB2 signaling on TXNIP mRNA expression. The later increase of TXNIP mRNA levels begins concomitant with the $G_{1}$ arrest of the MCF-7 cells as they undergo senescence [3]. Although the molecular mechanisms leading to the TXNIP biphasic behavior remain unknown, it fits the inverse correlation of TXNIP with the proliferation metagene observed in our study and it agrees with the known function of the TXNIP gene as a tumor suppressor [42].

The observed initial activation of TXNRD1 and repression of TXNIP transcription by ERBB2 signaling independent of ROS in our MCF-7/NeuT cell model could be interpreted as part of an ERBB2-triggered survival program that intends to prevent later accumulation of ROS. Further, it suggests that TXNIP and TXNRD1 are ERBB2 effectors whose multiple cellular functions contribute to proliferation, apoptosis resistance, metabolic reprogramming and, finally, to the hallmarks of ERBB2-positive breast tumors (Figure 6).

Accumulation of ROS in senescent MCF-7/NeuT cells (14 days) is accompanied by the recovery of TXNIP mRNA to initial levels, which is expected to negatively influence the ROS-scavenging activity of thioredoxin. This could therefore partially explain increased ROS at this stage. Interestingly, mRNA expression of thioredoxin itself decreases slightly in MCF-7/NeuT cells at 14 days (Additional file 9). Many other factors, however, are also likely to contribute to the late accumulation of ROS in senescent cells. This is under current investigation.

\section{Conclusions}

In the present article we have shown that high TXNRD1 expression and low TXNIP expression are associated with worse prognosis in node-negative breast cancer. ERBB2 can influence expression levels of TXNRD1 and TXNIP to shift balances in a prognostically unfavorable manner.

\section{Additional material}

Additional file 1 Clinicopathological characteristics of node-negative breast cancer patients. A pdf file containing a table that displays the clinicopathological characteristics of node-negative breast cancer patients from the Mainz, the Rotterdam and the Transbig cohorts.

Additional file 2 Frequency distribution of TXNRD1 and TXNIP RNA expression in the combined cohort. A pdf file showing frequency distribution of TXNRD1 and TXNIPRNA expression in the combined cohort of 788 patients with node-negative breast cancer.

Additional file 3 Frequency distributions of estrogen receptor, ERBB2 and progesterone receptor RNA expression in the combined cohort. A pdf file showing the frequency distributions of estrogen receptor, ERBB2 and progesterone receptor RNA expression in the combined cohort, allowing the identification of the cut-off points for dichotomization.

Additional file 4 Frequency distributions of estrogen receptor, ERBB2 and progesterone receptor RNA in the three individual cohorts. A pdf file showing the frequency distributions of estrogen receptor, ERBB2 and progesterone receptor RNA in the three individual cohorts (Mainz, Rotterdam and Transbig).

Additional file 5 Association of TXNRD1 and TXNIP RNA expression with the established clinical parameters in the combined cohort. A pdf file showing the association of TXNRD1 and TXNIP RNA expression with the established clinical parameters age, pT stage, grading, hormone receptor as well as ERBB2 status in the combined cohort of 788 patients with nodenegative breast cancer.

Additional file 6 Phenotypical alterations of MCF-/NeuT cells in the first 3 days after NeuT induction. A videoclip showing phenotypical alterations of MCF-/NeuT cells in the first 3 days after NeuT induction. The transition from the proliferating into the senescent state is evident.

Additional file 7 Upregulation of $P 21$ in doxycycline-induced, ERBB2 (NeuT)-overexpressing MCF-7 cells. A pdf file showing upregulation of P21 in doxycycline-induced, ERBB2 (NeuT)-overexpressing MCF-7 cells as assayed by quantitative real-time PCR.

Additional file 8 Accumulation of ROS 14 days after onset of ERBB2 (NeuT) overexpression in doxycycline-induced MCF-7 cells. A pdf file showing increase in the accumulation of ROS 14 days after onset of ERBB2 (NeuT) overexpression in doxycycline-induced MCF-7 cells, as determined by the lipid peroxidation assay LPO-586 (Oxis Research).

Additional file 9 RNA levels of thioredoxin. A pdf file showing RNA levels of thioredoxin, assayed by Affymetrix gene arrays in MCF-7/NeuT cells.

\section{Abbreviations}

DETBA: 1,3-diethyl-2-thiobarbituric acid; GEO: Gene Expression Omnibus; HIF1: hypoxia inducible factor 1; HR: hazard ratio; MDA: malondialdehyde; MFI: metastasis-free interval; NF: nuclear factor; PCR: polymerase chain reaction; ROS: reactive oxygen species; TGT: mean target intensity; TNXRD 1: thioredoxin reductase 1; TXNIP: thioredoxin interacting protein; VEGF: vascular endothelial growth factor.

\section{Competing interests}

MG is employed by Siemens Healthcare Diagnostics Products $\mathrm{GmbH}$, which is in the business of commercializing diagnostic products. The other authors declare that they have no competing interests. 


\section{Authors' contributions}

CC and JGH contributed to the study conception and design, analysis and interpretation of collected data, and drafted and revised the manuscript critically for important intellectual content. DF, MSchu and LM carried out the realtime PCR experiments in MCF-7 cells. MSchm collected patient-related tissue and data, and contributed to the design of the study. MG carried out the gene array expression analysis of patient tissue and contributed to the design of the study. MH carried out the gene array expression analysis of MCF-7/NeuT cells. BG and WS characterized the MCF-7/NeuT cell system and performed the immunoblot assays. ASc and CW carried out the lipid peroxidation assays. EF, KI and JR performed the statistical analysis. JIB and ASi participated in study design and coordination, and revised the manuscript for important intellectual content. All authors read and approved the final manuscript.

\section{Acknowledgements}

The present study was supported by the NGFN-BMBF project OncoProfile. The authors dedicate this work to Alexander Bauer.

\section{Author Details}

'Department of Bioanalytics, Leibniz-Institut für Analytische Wissenschaften ISAS - e.V., Bunsen-Kirchhoff-Straße 11, Dortmund 44139, Germany, 2Systems Toxicology, Leibniz Research Centre for Working Environment and Human Factors (IfADo) at the TU Dortmund University, Ardeystraße 67, Dortmund 44139, Germany, ${ }^{3}$ Department of Obstetrics and Gynecology, University Medical Center, Langenbeckstraße 1, Mainz 55131 Germany, 4H DX DB Molecular Research Koeln, Siemens Healthcare Diagnostics Products GmbH, Nattermannallee 1, Koeln 50829, Germany, 5Department of Plant Physiology, University of Leipzig, Johannisallee 21-23, Leipzig 04103, Germany and 6Department of Statistics, TU Dortmund University, Vogelpothsweg 87, Dortmund 44221, Germany

Received: 1 February 2010 Revised: 10 June 2010 Accepted: 28 June 2010 Published: 28 June 2010

\section{References}

1. Schumacker PT: Reactive oxygen species in cancer cells: live by the sword, die by the sword. Cancer Cell 2006, 10:175-176.

2. Trachootham D, Zhou Y, Zhang H, Demizu Y, Chen Z, Pelicano H, Chiao PJ, Achanta G, Arlinghaus RB, Liu J, Huang P: Selective killing of oncogenically transformed cells through a ROS-mediated mechanism by beta-phenylethyl isothiocyanate. Cancer Cell 2006, 10:241-252.

3. Trost TM, Lausch EU, Fees SA, Schmitt S, Enklaar T, Reutzel D, Brixel LR, Schmidtke P, Maringer M, Schiffer IB, Heimerdinger CK, Hengstler JG, Fritz G, Bockamp EO, Prawitt D, Zabel BU, Spangenberg C: Premature senescence is a primary fail-safe mechanism of ERBB2-driven tumorigenesis in breast carcinoma cells. Cancer Res 2005, 65:840-849.

4. Spangenberg C, Lausch EU, Trost TM, Prawitt D, May A, Keppler R, Fees SA, Reutzel D, Bell C, Schmitt S, Schiffer IB, Weber A, Brenner W, Hermes M, Sahin U, Tureci O, Koelbl H, Hengstler JG, Zabel BU: ERBB2-mediated transcriptional up-regulation of the $\alpha_{5} \beta_{1}$ integrin fibronectin receptor promotes tumor cell survival under adverse conditions. Cancer Res 2006, 66:3715-3725

5. Chen KS, DeLuca HF: Isolation and characterization of a novel CDNA from HL-60 cells treated with 1,25-dihydroxyvitamin D-3. Biochim Biophys Acta 1994, 1219:26-32.

6. Hayashi T, Ueno Y, Okamoto T: Oxidoreductive regulation of nuclear factor kappa B. Involvement of a cellular reducing catalyst thioredoxin. J Biol Chem 1993, 268:11380-11388.

7. Ueno M, Masutani H, Arai RJ, Yamauchi A, Hirota K, Sakai T, Inamoto T, Yamaoka Y, Yodoi J, Nikaido T: Thioredoxin-dependent redox regulation of p53-mediated p21 activation. J Biol Chem 1999, 274:35809-35815.

8. Arner ES, Holmgren A: The thioredoxin system in cancer. Semin Cancer Biol 2006, 16:420-426.

9. Nishiyama A, Matsui M, Iwata S, Hirota K, Masutani H, Nakamura H, Takagi $Y$, Sono $\mathrm{H}$, Gon $Y$, Yodoi J: Identification of thioredoxin-binding protein2/vitamin $D(3)$ up-regulated protein 1 as a negative regulator of thioredoxin function and expression. J Biol Chem 1999, 274:21645-21650

10. Yamanaka H, Maehira F, Oshiro M, Asato T, Yanagawa Y, Takei $H$, Nakashima Y: A possible interaction of thioredoxin with VDUP1 in HeLa cells detected in a yeast two-hybrid system. Biochem Biophys Res Commun 2000, 271:796-800.

11. Junn E, Han SH, Im JY, Yang Y, Cho EW, Um HD, Kim DK, Lee KW, Han PL, Rhee SG, Choi I: Vitamin D3 up-regulated protein 1 mediates oxidative stress via suppressing the thioredoxin function. J Immuno/ 2000, 164:6287-6295.

12. Chen CL, Lin CF, Chang WT, Huang WC, Teng CF, Lin YS: Ceramide induces $\mathrm{p} 38$ MAPK and JNK activation through a mechanism involving a thioredoxin-interacting protein-mediated pathway. Blood 2008, 111:4365-4374.

13. Chung JW, Jeon JH, Yoon SR, Choi I: Vitamin D3 upregulated protein 1 (VDUP1) is a regulator for redox signaling and stress-mediated diseases. J Dermatol 2006, 33:662-669.

14. Kim SY, Suh HW, Chung JW, Yoon SR, Choi I: Diverse functions of VDUP1 in cell proliferation, differentiation, and diseases. Cell Mol Immunol 2007, 4:345-351.

15. Muoio DM: TXNIP links redox circuitry to glucose control. Cell Metab 2007, 5:412-414

16. Hui ST, Andres AM, Miller AK, Spann NJ, Potter DW, Post NM, Chen AZ, Sachithanantham S, Jung DY, Kim JK, Davis RA: Txnip balances metabolic and growth signaling via PTEN disulfide reduction. Proc Natl Acad Sci USA 2008, 105:3921-3926.

17. Urig S, Becker K: On the potential of thioredoxin reductase inhibitors for cancer therapy. Semin Cancer Biol 2006, 16:452-465.

18. Powis $G$, Kirkpatrick DL: Thioredoxin signaling as a target for cancer therapy. Curr Opin Pharmacol 2007, 7:392-397.

19. Yoo MH, Xu XM, Carlson BA, Gladyshev VN, Hatfield DL: Thioredoxin reductase 1 deficiency reverses tumor phenotype and tumorigenicity of lung carcinoma cells. J Biol Chem 2006, 281:13005-13008.

20. Wells G, Berry JM, Bradshaw TD, Burger AM, Seaton A, Wang B, Westwell $A D$, Stevens MF: 4-Substituted 4-hydroxycyclohexa-2,5-dien-1-ones with selective activities against colon and renal cancer cell lines. J Med Chem 2003, 46:532-541.

21. Mukherjee A, Westwell AD, Bradshaw TD, Stevens MF, Carmichael J, Martin SG: Cytotoxic and antiangiogenic activity of AW464 (NSC 706704), a novel thioredoxin inhibitor: an in vitro study. Br J Cancer 2005, 92:350-358.

22. Bradshaw TD, Matthews CS, Cookson J, Chew EH, Shah M, Bailey K, Monks A, Harris E, Westwell AD, Wells G, Laughton CA, Stevens MF: Elucidation of thioredoxin as a molecular target for antitumor quinols. Cancer Res 2005, 65:3911-3919.

23. Kim SJ, Miyoshi Y, Taguchi T, Tamaki Y, Nakamura H, Yodoi J, Kato K, Noguchi S: High thioredoxin expression is associated with resistance to docetaxel in primary breast cancer. Clin Cancer Res 2005, 11:8425-8430.

24. Iwao-Koizumi K, Matoba R, Ueno N, Kim SJ, Ando A, Miyoshi Y, Maeda E, Noguchi S, Kato K: Prediction of docetaxel response in human breast cancer by gene expression profiling. J Clin Oncol 2005, 23:422-431.

25. Raffel J, Bhattacharyya AK, Gallegos A, Cui H, Einspahr JG, Alberts DS, Powis G: Increased expression of thioredoxin-1 in human colorectal cancer is associated with decreased patient survival. J Lab Clin Med 2003, 142:46-51.

26. Kakolyris S, Giatromanolaki A, Koukourakis M, Powis G, Souglakos J, Sivridis E, Georgoulias V, Gatter KC, Harris AL: Thioredoxin expression is associated with lymph node status and prognosis in early operable non-small cell lung cancer. Clin Cancer Res 2001, 7:3087-3091.

27. Tome ME, Johnson DB, Rimsza LM, Roberts RA, Grogan TM, Miller TP, Oberley LW, Briehl MM: A redox signature score identifies diffuse large B-cell lymphoma patients with a poor prognosis. Blood 2005, 106:3594-3601.

28. Schug M, Heise T, Bauer A, Storm D, Blaszkewicz M, Bedawy E, Brulport M, Geppert B, Hermes M, Follmann W, Rapp K, Maccoux L, Schormann W, Appel KE, Oberemm A, Gundert-Remy U, Hengstler JG: Primary rat hepatocytes as in vitro system for gene expression studies: comparison of sandwich, Matrigel and 2 D cultures. Arch Toxicol 2008 , 82:923-931.

29. Hermes M, Schormann W, Brulport M, Uhlemann K, Lupatsch F, Horn LC, Schumann A, Allgaier C, Weishaupt M, Engeland K, Muller GA, Mossner J, Bauer A, Schiffer IB, Gebhard S, Schmidt M, Lausch E, Prawitt D, Wilhelm C, Hengstler JG: Trastuzumab therapy vs tetracycline controlled ERBB2 downregulation: influence on tumour development in an ERBB2dependent mouse tumour model. Br J Cancer 2008, 98:1525-1532. 
30. Schumann A, Bauer A, Hermes M, Gilbert M, Hengstler JG, Wilhelm C: A rapid and easy to handle thermoluminescence based technique for evaluation of carbon tetrachloride-induced oxidative stress on rat hepatocytes. Arch Toxicol 2009, 83:709-720.

31. Schmidt M, Bohm D, von Torne C, Steiner E, Puhl A, Pilch H, Lehr HA, Hengstler JG, Kolbl H, Gehrmann M: The humoral immune system has a key prognostic impact in node-negative breast cancer. Cancer Res 2008, 68:5405-5413.

32. Wang Y, Klijn JG, Zhang Y, Sieuwerts AM, Look MP, Yang F, Talantov D, Timmermans M, Meijer-van Gelder ME, Yu J, Jatkoe T, Berns EM, Atkins D, Foekens JA: Gene-expression profiles to predict distant metastasis of lymph-node-negative primary breast cancer. Lancet 2005, 365:671-679.

33. Loi S, Haibe-Kains B, Desmedt C, Lallemand F, Tutt AM, Gillet C, Ellis P, Harris A, Bergh J, Foekens JA, Klijn JG, Larsimont D, Buyse M, Bontempi G, Delorenzi M, Piccart MJ, Sotiriou C: Definition of clinically distinct molecular subtypes in estrogen receptor-positive breast carcinomas through genomic grade. J Clin Oncol 2007, 25:1239-1246.

34. Desmedt C, Piette F, Loi S, Wang Y, Lallemand F, Haibe-Kains B, Viale G, Delorenzi M, Zhang Y, d'Assignies MS, Bergh J, Lidereau R, Ellis P, Harris AL, Klijn JG, Foekens JA, Cardoso F, Piccart MJ, Buyse M, Sotiriou C: Strong time dependence of the 76-gene prognostic signature for nodenegative breast cancer patients in the TRANSBIG multicenter independent validation series. Clin Cancer Res 2007, 13:3207-3214

35. Schmidt M, Hengstler JG, von Torne C, Koelbl H, Gehrmann MC: Coordinates in the universe of node-negative breast cancer revisited. Cancer Res 2009, 69:2695-2698.

36. Schmidt M, Victor A, Bratzel D, Boehm D, Cotarelo C, Lebrecht A, Siggelkow W, Hengstler JG, Elsasser A, Gehrmann M, Lehr HA, Koelbl H, von Minckwitz G, Harbeck N, Thomssen C: Long-term outcome prediction by clinicopathological risk classification algorithms in nodenegative breast cancer - comparison between Adjuvant!, St Gallen, and a novel risk algorithm used in the prospective randomized NodeNegative-Breast Cancer-3 (NNBC-3) trial. Ann Oncol 2009, 20:258-264.

37. Freis E, Selinski S, Weibert B, Krahn U, Schmidt M, Gehrmann M, Hermes M, Maccoux L, West J, Schwender H, Rahnenführer J, Hengstler JG: Effects of metagene calculation on survival: an integrative approach using cluster and promoter analysis. In Sixth International Workshop on Computational Systems Biology; 10-12 June 2009; Aarhus. TISCP series \# 48 Edited by: Manninen T, Wiuf C, Lähdesmäki H, Grzegorczyk M, Rahnenführer J, Ahdesmäki M, Linne M-L, Yli-Harja O. Tampere: TISCP; 2009.

38. Schmidt M, Hasenclever D, Schaeffer M, Boehm D, Cotarelo C, Steiner E, Lebrecht A, Siggelkow W, Weikel W, Schiffer-Petry I, Gebhard S, Pilch H, Gehrmann M, Lehr HA, Koelbl H, Hengstler JG, Schuler M: Prognostic effect of epithelial cell adhesion molecule overexpression in untreated node-negative breast cancer. Clin Cancer Res 2008, 14:5849-5855.

39. Lu J, Chew EH, Holmgren A: Targeting thioredoxin reductase is a basis for cancer therapy by arsenic trioxide. Proc Natl Acad Sci USA 2007, 104:12288-12293.

40. Jones DT, Pugh CW, Wigfield S, Stevens MF, Harris AL: Novel thioredoxin inhibitors paradoxically increase hypoxia-inducible factor-alpha expression but decrease functional transcriptional activity, DNA binding, and degradation. Clin Cancer Res 2006, 12:5384-5394.

41. Ravi D, Muniyappa H, Das KC: Endogenous thioredoxin is required for redox cycling of anthracyclines and p53-dependent apoptosis in cancer cells. J Biol Chem 2005, 280:40084-40096.

42. Kim WJ, Cho H, Lee SW, Kim YJ, Kim KW: Antisense-thioredoxin inhibits angiogenesis via $\mathrm{pVHL}$-mediated hypoxia-inducible factor-1a degradation. Int J Oncol 2005, 26:1049-1052.

43. Shin D, Jeon JH, Jeong M, Suh HW, Kim S, Kim HC, Moon OS, Kim YS, Chung JW, Yoon SR, Kim WH, Choi I: VDUP1 mediates nuclear export of HIF1a via CRM1-dependent pathway. Biochim Biophys Acta 2008, 1783:838-848.

44. Takahashi Y, Masuda H, Ishii Y, Nishida Y, Kobayashi M, Asai S: Decreased expression of thioredoxin interacting protein mRNA in inflamed colonic mucosa in patients with ulcerative colitis. Oncol Rep 2007, 18:531-535.

45. Lincoln DT, Ali Emadi EM, Tonissen KF, Clarke FM: The thioredoxinthioredoxin reductase system: over-expression in human cancer. Anticancer Res 2003, 23:2425-2433.

46. Han $\mathrm{SH}$, Jeon JH, Ju HR, Jung U, Kim KY, Yoo HS, Lee YH, Song KS, Hwang $H M, N a$ YS, Yang Y, Lee KN, Choi I: VDUP1 upregulated by TGF- $\beta 1$ and 1,25-dihydorxyvitamin D3 inhibits tumor cell growth by blocking cellcycle progression. Oncogene 2003, 22:4035-4046.

47. Butler LM, Zhou X, Xu WS, Scher HI, Rifkind RA, Marks PA, Richon VM: The histone deacetylase inhibitor SAHA arrests cancer cell growth, upregulates thioredoxin-binding protein-2, and down-regulates thioredoxin. Proc Natl Acad Sci USA 2002, 99:11700-11705.

48. Schwertassek U, Balmer Y, Gutscher M, Weingarten L, Preuss M, Engelhard J, Winkler M, Dick TP: Selective redox regulation of cytokine receptor signaling by extracellular thioredoxin-1. EMBO J 2007, 26:3086-3097.

49. Moody SE, Sarkisian CJ, Hahn KT, Gunther EJ, Pickup S, Dugan KD, Innocent N, Cardiff RD, Schnall MD, Chodosh LA: Conditional activation of Neu in the mammary epithelium of transgenic mice results in reversible pulmonary metastasis. Cancer Cell 2002, 2:451-461.

50. Moody SE, Perez D, Pan TC, Sarkisian CJ, Portocarrero CP, Sterner CJ, Notorfrancesco KL, Cardiff RD, Chodosh LA: The transcriptional repressor Snail promotes mammary tumor recurrence. Cancer Cell 2005, 8:197-209.

51. Giraud MN, Fluck M, Zuppinger C, Suter TM: Expressional reprogramming of survival pathways in rat cardiocytes by neuregulin13. J Appl Physiol 2005, 99:313-322.

52. Chen ZH, Saito Y, Yoshida Y, Sekine A, Noguchi N, Niki E: 4Hydroxynonenal induces adaptive response and enhances $\mathrm{PC} 12$ cell tolerance primarily through induction of thioredoxin reductase 1 via activation of Nrf2. J Biol Chem 2005, 280:41921-41927.

doi: $10.1186 /$ bcr2599

Cite this article as: Cadenas et al., Role of thioredoxin reductase 1 and thioredoxin interacting protein in prognosis of breast cancer Breast Cancer Research 2010, 12:R44

\section{Submit your next manuscript to BioMed Central and take full advantage of:}

- Convenient online submission

- Thorough peer review

- No space constraints or color figure charges

- Immediate publication on acceptance

- Inclusion in PubMed, CAS, Scopus and Google Scholar

- Research which is freely available for redistribution

Submit your manuscript at www.biomedcentral.com/submit
C Biomed Central 